Conclusions: In the persistent UA group and CCP-RA group, WBMRI findings at baseline already showed a definite pattern of spinal disease. Therefore the use of WBMRI findings at presentation in addition to clinical assessment would allow clinicians to classify a proportion of patients earlier.

Disclosure of Interest: None declared

DOI: 10.1136/annrheumdis-2017-eular.5051

\section{FRI0631 PREDICTIVE VALUE OF POWER DOPPLER ULTRASONOGRAPHY (PDUS) IN THE DIAGNOSIS OF EARLY RHEUMATOID ARTHRITIS}

L. Mayordomo $^{1}$, C. Jurado ${ }^{2}$, M.L. Velloso ${ }^{1}$, A. Gutierrez-Leonard ${ }^{3}$,

P. González-Moreno ${ }^{4}$, J.L. Marenco ${ }^{1}$, C. Almeida ${ }^{5} \cdot{ }^{1}$ Rheumatology Department;

${ }^{2}$ Radiology Dp, Hospital Universitario Valme; ${ }^{3}$ Physioterapy, HVR;

${ }^{4}$ Rheumatology Department, HVM; ${ }^{5}$ Research and Statistics Dp, Hospital Universitario Valme, SEVILLA, Spain

Background: There is a short window of opportunity for early diagnosis and treatment of rheumatoid arthritis, that may be crucial for reaching remission and a low rate of radiographic progression. High resolution power doppler ultrasonography (PDUS) is helpful in early detection of synovitis and allows an accurate classification of patients with joint inflammation.

Objectives: To establish wether the presence of basal power doppler signal in patients with very early arthritis may be helpful in order to establish the risk of final diagnosis of rheumatoid arthritis according ACR criteria 1987 at a year of follow up.

Methods: We studied the presence of ultrasonographic Power Doppler (PD) signal on 28 joints (shoulders, elbows, wrists, MCPs, PIPs, knees) and 44 joints (28 joints and in addition hips, ankles, tarsus, and MTPs), with a mid-range equipment GE L5, in 70 patients with suspected early arthritis The patients were included with at least one of the following inclusion criteria: a) Swelling in 2 or more joints b) pain in MCPs, MTPs and/or the wrists c) morning stiffness of more than 30 minutes with $<12$ months of duration of the symptoms. Presence or not basal erosions (score $\geq 2$ in at least one joint by modified Sharp method) for each patient were registered (65 patients with basal hands and feet radiology available). Presence of RF and ACPA positive were recorded as well. At one year follow-up was established whether patients met criteria for RA according1987 ACR or not. Statistical study: Chi-square, Fisher exact test, p univariant and Odds Ratio calculation.

Results: The presence of basal power doppler signal in $\geq 1$ joints of 44 (PD44) in baseline visit shows statistically significant association to RA diagnosis at 12 months by ACR 1987 classification criteria, $p=0.003$, OR=5,43 $(1,71-17,24)$ but the presence of at least one joint with power doppler signal of 28 joints (PD28) did not $(\mathrm{p}=0.051)$. Presence hypertrophic synovium with PD44 or not, in at least one joint (HSORPD44) was associated to RA diagnosis as well $p=0.024$; OR $10,24(1,12-93,28)$. RF was positive in $18 / 70(25,71 \%)$ and was associated to RA diagnosis ( $\mathrm{p} 0.003$, OR $8,31(1,74-39,64)$, as well as FR/ACPA, positive in $20 / 70(28,57 \%), p=0.001$ OR $10(2,10-47,58)$. PD44 in addition to positive $\mathrm{RF}$ was associated to RA $p=0.003$, OR $12,93(1,59-104,94)$. Presence of basal radiographic erosions (BRE) was associated to $\mathrm{RA}, \mathrm{p}=0.001$ OR $7,72(2,2-26,8)$. PD44 in addition to BRE was significantly associated to RA $p=0.0005$, OR $29,33(3,61-238,37)$. PD28 in addition to RF or BRE was significantly associated to $R A$ respectively $p 0.0005$ OR $24,20(2,98-196.34)$ and $p=0.003$ OR 12,93 $(1,59-104,94)$.

\begin{tabular}{|c|c|c|c|c|c|}
\hline \multicolumn{2}{|l|}{ BASAL } & RA YES & D & OR & CI $95 \%$ \\
\hline PD 44 & $\begin{array}{r}\text { YES } \\
\text { NO }\end{array}$ & $\begin{array}{c}38 / 52(73,1 \%) \\
6 / 18(33,3 \%)\end{array}$ & 0.003 & 5,43 & $(1,71-17,24)$ \\
\hline PD44+FR & $\begin{array}{l}\text { YES } \\
\text { NO }\end{array}$ & $\begin{array}{l}15 / 16(93,9 \%) \\
29 / 54(53,7 \%)\end{array}$ & 0.003 & 12,93 & $(1,59-104,94)$ \\
\hline $\begin{array}{l}\text { PD44+BAS EROS } \\
n=65\end{array}$ & $\begin{array}{l}\text { YES } \\
\text { NO }\end{array}$ & $\begin{array}{l}24 / 25(96 \%) \\
18 / 40(45 \%)\end{array}$ & 0.0005 & 29,33 & $(3,61-238,37)$ \\
\hline HSORPD 44 & $\begin{array}{l}\text { YES } \\
\text { NO }\end{array}$ & $\begin{array}{c}43 / 64(67,19 \%) \\
1 / 6(16,6 \%)\end{array}$ & 0.024 & 10,24 & $(1,12-93,28)$ \\
\hline $\begin{array}{l}\text { BAS EROS } \\
n=65\end{array}$ & $\begin{array}{r}\text { YES } \\
\text { NO }\end{array}$ & $\begin{array}{l}26 / 30(86,7 \%) \\
16 / 35(45,7 \%)\end{array}$ & 0.001 & 7,72 & $(2,2-26,8)$ \\
\hline FR & $\begin{array}{l}\text { YES } \\
\text { NO }\end{array}$ & $\begin{array}{l}18 / 20(90 \%) \\
26 / 50(52 \%)\end{array}$ & 0.003 & 8,31 & $(1,74-39,64)$ \\
\hline FR/PCC & $\begin{array}{r}\text { YES } \\
\text { NO }\end{array}$ & $\begin{array}{c}20 / 22(90,9 \%) \\
24 / 48(50 \%)\end{array}$ & 0.001 & 10 & $(2,10-47,58)$ \\
\hline
\end{tabular}

Conclusions: The presence of at least one joint with power doppler signal of 44 joints (PD44) on baseline visit may help to predict the RA diagnosis at 12 months of follow up according to criteria ACR 1987, in patients with early RA. PD 44 in addition to classic RA factors (RF and basal radiographic erosions) increased the risk final of RA, till more than three times in case of concomitant basal PD44 and radiographic erosions.

Disclosure of Interest: None declared

DOI: 10.1136/annrheumdis-2017-eular.6282

\section{FRI0632 MRI-US FUSION IMAGES FOR RHEUMATOID ARTHRITIS: CAN DOPPLER SUBSTITUTE FOR GADOLINIUM?}

F. Barbieri ${ }^{1}$, A. Muda ${ }^{2}$, S. Migone ${ }^{2}$, V. Prono ${ }^{2}$, I. Mussetto ${ }^{2}$, N. Romano ${ }^{2}$, A. Fischetti ${ }^{3}$, V. Tomatis ${ }^{1}$, S. Paolino ${ }^{4}$, M. Cutolo $^{4}$, G. Garlaschi ${ }^{2}$,

M.A. Cimmino ${ }^{1} .{ }^{1}$ Dipartimento di Medicina Interna, Clinica Reumatologica;

${ }^{2}$ Sezione di Radiologia; ${ }^{3}$ Università di Genova; ${ }^{4}$ Clinica Reumatologica, Genova, Italy

Background: $\mathrm{MRI}$ is increasingly used to objectively assess disease activity and damage in patients with rheumatoid arthritis (RA), especially in clinical trials. The preferred scoring method is the RAMRIS, which implies the use of gadolinium, an intravenous contrast agent, to assess synovitis.

Objectives: We evaluated in a small preliminary study if the fusion of MRI and US Power Doppler (PD) images could avoid gadolinium.

Methods: 12 patients (10 women) affected by RA, with at least one involved wrist, were studied. Mean age was $58.8 \pm 9.1$ years and mean disease duration was $54.5 \pm 56.1$ months. Disease activity (DAS 28-CRP) was evaluated on the day of the examinations.

MRI was performed on a extremity-dedicated machine (Oscan $0.3 \mathrm{~T}$, Esaote, Genova Italy) and US by MyLab Twice ultrasound scanner with a virtual navigator software (Esaote, Genova, Italy). T3Dt1 sequences were used in the fusion images (parameters: TR/TE/NEX 38/16/1, matrix 192*192*39, FOV 160*160*60, thickness $0.6 \mathrm{~mm}$ ). US scans were performed sagittally on the radio-lunate joint and axially on the proximal carpal bones of the dorsal wrist with B-mode and PD (PRF $500-750 \mathrm{~Hz}$; WF: 3; maximum gain with probe's calibration in air). Magnetic position sensor linked to the US transducer $(13 \mathrm{MHz})$ and low magnetic field transmitters were used to allowed fusion images.

MRI synovitis was scored by the RAMRIS and with the contrast-enhanced dynamic method resulting in rate of early enhancement (REE) and relative enhancement, (RE). The US score was the Global OMERACT-EULAR Synovitis Score (GLOESS) and its individual parts.

Results: Inter-reader agreement for PD by weighted kappa was $0.75(75 \% \mathrm{Cl}$ $0.53-0.96)$ for the sagittal and $1(75 \% \mathrm{Cl} 1-1)$ for the axial view. It was 0.85 (75\% Cl 0.69-0.98) for MRI synovitis.

There was a correlation between DAS28 and the MRI synovits score $(r=0.59$, $p=0.04)$, REE $(r=0.60, p=0.04)$, and $R E(r=0.58, p=0.05)$, US Doppler in the long $(r=0.75, p=0.005)$ and in the axial axes $(r=0.86, p=0.01)$, but not with B-mode synovial effusion $(r=0.56, p=0.056)$. The GLOESS correlated with DAS28 $(r=0.66$, $\mathrm{p}=0.019$ ), but not with RAMRIS synovitis, erosions or BME nor with REE. The MRI wrist synovitis score did not correlate with the Doppler score on the sagittal and axial views, nor with US B mode score. This was true also for the three individual MRI slices of the wrist, the REE and the RE. The figure shows from the left the pre-contrast axial MRI image, the post-contrast and the fusion images.

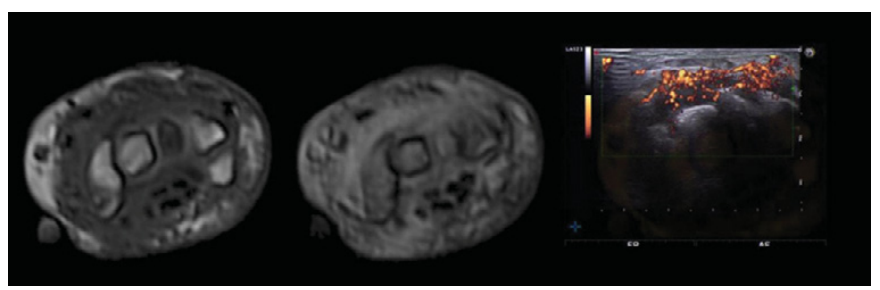

Conclusions: Although both MRI and Doppler are good indicators of disease activity in RA, they seem not to be interchangeable. This may be due to the fact that MRI and US show different features of synovitis or, alternatively, that MRI comprised the whole wrist whereas US visualized only its dorsal area. Although our preliminary data do not support the use of fusion images, these should be investigated on larger number of patients with a more extended PD approach.

Disclosure of Interest: None declared

DOI: 10.1136/annrheumdis-2017-eular.5433

\section{FRI0633 WHICH ARE THE ULTRASOUND LESIONS UNDERLYING DACTYLITIS?}

A. Nzeusseu Toukap ${ }^{1,2}$, T. Kirchgesner ${ }^{3}$, F. Lecouvet ${ }^{1,3}$, P. Navarro ${ }^{2}$, B. Vande Berg $^{1,3}$, A. Durnez ${ }^{2}$, M.S. Stoenoiu ${ }^{1,2}{ }^{1}$ Institut de Recherche Expérimentale et Clinique (IREC), Université catholique de Louvain; ${ }^{2}$ Rheumatology department; ${ }^{3}$ Radiology department, Cliniques Universitaires Saint-Luc, Brussels, Belgium

Background: Dactylitis, defined as a diffuse swelling of a digit is a hallmark feature of peripheral spondyloarthritis $(\mathrm{SpA})$, particularly in psoriatic arthritis, with a prevalence between $16 \%$ and $48^{1}$

Objectives: This study aims to assess the frequency of the pathological lesions in dactylitis using ultrasonography (US) and to evaluate their association with patient-reported tenderness.

Methods: Thirty-four dactylitis from 20 consecutive patients suffering from peripheral spondyloarthritis were examined by ultrasound. At US examination, the entire digit was scanned both on dorsal and palmar/plantar sides. The following US pathological lesions were scored: soft tissue thickness, soft tissue edema, soft tissue vascularization, synovitis of metacarpophalangeal (MCP)/metatarsophalangeal (MTP), of proximal interphalangeal (PIP) and of 
distal interphalangeal (DIP) joints, inflammatory involvement of both flexor (tenosynovitis) and extensor (paratenonitis) tendons, nail bed vascularization, synovio-entheseal complex at DIP level, enthesitis of flexor tendon, and bone proliferation. Grey-scale (GS) and power-Doppler (PD) synovitis and tenosynovitis were assessed according to OMERACT scores (0-3). Nail bed vascularization was scored 0 to 3 . The other US lesions were scored 0 (absent) or 1 (present), both in GS and PD. The standard (HAQ) questionnaire, tender and swollen joint count, patient-reported tenderness, global disease activity scored by physician and by patient were assessed in all patients.

Results: Twelve (60\%) patients presented hand and $8(40 \%)$ patients foot dactylitis. Twelve $(60 \%)$ patients had single dactylitis. Eight patients presented with multiple dactylitis: 4 dactylitis in 1 patient, $(5 \%), 3$ dactylitis in 4 patients $(20 \%)$ patients and 2 dactylitis in $3(15 \%)$ patients. Soft tissue thickening was present in all 34 dactylitis. MCP/MTP joint synovitis was present in 28 digits (82\%), PIP joint synovitis in 23 digits $(68 \%)$ and DIP joint synovitis in 17 digits (50\%). Extensor paratenonitis was observed in 21 digits $(62 \%)$ and flexor tenosynovitis in 20 digits $(59 \%)$. Enthesitis of extensor tendons was present in 21 digits $(62 \%)$ and enthesitis of flexor tendon in 5 digits $(15 \%)$. Osteoproliferation was present in 21 digits (62\%). The frequency of synovitis, tenosynovitis and enthesitis did not differ significantly between tender $(n=25)$ and non-tender $(n=9)$ dactylitis. A significant association between tenderness and the presence of power Doppler $\left(\chi^{2}: 17.9\right.$, $p<0.01)$ and of edema in the soft tissue was observed $\left(x^{2}: 11.5, p<0.01\right)$.

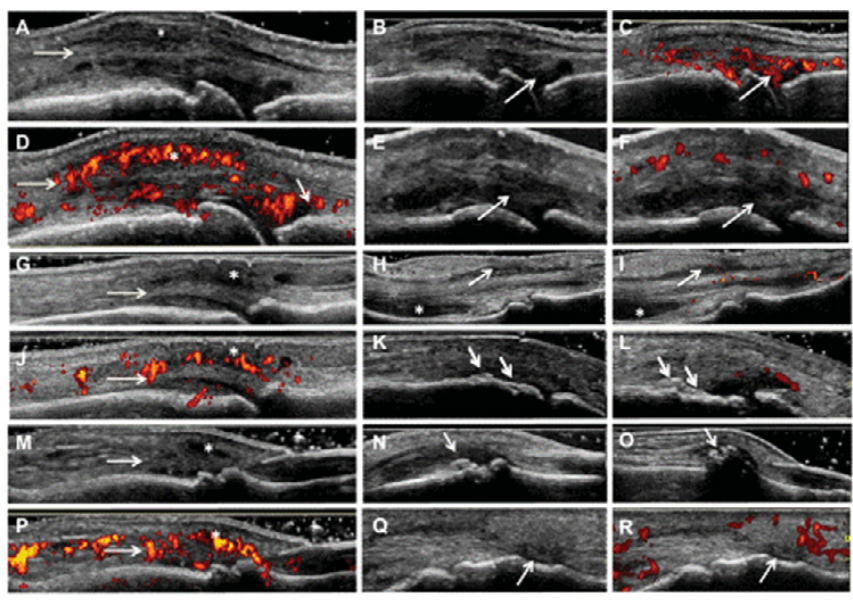

Figure. Ultrasound lesions in dactvlitis. Longitudinal scans of digital extensor tendons in GS (AG,M) and in PD (D, J, P) US showed extensive peritendinous inflammation. Note the tendor thickenim (AGM the loss of fbrillar pattern (AG) and hypochorenicity (A $M$ of the extenso thich at the synovio-entheaseal complex at the DIP joint (MP) (arrows in panels A,D,G,J,MP indicate digital extensor tendon and asterisks indicate anechoic or hypoechoic material around the dorsal extensor tendon with PD signals). Longitudinal US scans of $M C^{2}$ and $P I P$ joints in $G S(B, E)$ and $P D$ $\mathrm{C}, F)$ mode. PD positive $(C)$ and $P D D$ oppler negative $(F)$ synovitis at the $\mathrm{MCP}$ joint $(B, C)$ and at the $P \mathbb{P}$ joint $(E, F)$. Note the pericapsular $P D$ signals in panel $F$ (arrows in panels $B, C, E, F$ indicate synovial hyperthrophy) with (C) or without (F) PD signals. Longitudinal scans of digital flex or tendor (HI) at the PP joint. Tenosynovitis of flexor digital tendon is depicted in GS $(H)$ and $P D(1)$ mode.

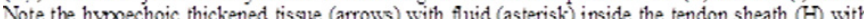
few synovial and intra-tendinous PD signals (I). Osteoproliferation at the PIP joint (KI) and at the $D P$ joint $(N, O)$ depicted in longitudinal scans. Enthe sitis of digital flex or tendon is depicted in GS (Q) and $P D(R)$. The latter finding is rare (arrows indicate enthe sitis).

Conclusions: Dactylitis is a multi-compartment digit disease, and anatomical lesions are more heterogenous than previously described. A significant amount of joint, tendon and entheseal inflammation persists in non-tender dactylitis. Patient-reported tenderness is associated with the presence of edema and/or power Doppler inside the soft tissue.

References:

[1] Bakewell CJ et al. OMERACT Ultrasound Task Force. Ultrasound and magnetic resonance imaging in the evaluation of psoriatic dactylitis: status and perspectives. J Rheumatol. 2013;40:1951-7.

Acknowledgements: We acknowledge S. Aydin and the OMERACT/EULAR working group for fruitful discussions.

Disclosure of Interest: None declared

DOI: 10.1136/annrheumdis-2017-eular.2283

\section{FRI0634 DO ANTHROPOMETRIC FACTORS INFLUENCE MEDIAN NERVE SIZE IN HEALTHY INDIVIDUALS? AN ULTRASOUND AND VOLUMETRY STUDY}

A. O'Neill, P. Gardiner, D. McCormick, E. Savage, D. Small. Rheumatology, Western Health and Social Care Trust, Londonderry, United Kingdom

Background: Some (but not all) ultrasound studies of median nerve dimensions at the wrist have suggested that anthropometric factors such as height and weight are among the possible sources of variability in the normal population but this has not been systematically studied ${ }^{1}$.

Objectives: The purpose of our study was to establish if hand and wrist volume or other standard anthropomorphic factors influenced median nerve size in normal subjects using standard ultrasonographic techniques. If median nerve size is predictably related to anthropomorphic factors, adjusted normal reference ranges would improve the diagnostic precision of the test for carpal tunnel syndrome.

Methods: We studied 30 healthy subjects: 14 females and 16 males. We measured their height, weight, arm span, finger span and wrist circumference. Ultrasonography of the median nerve was carried out at the entrance to the carpal tunnel and at a second level $2 \mathrm{~cm}$ proximal to the wrist using an Esaote MyLab Class C ultrasound with a $12-18 \mathrm{MHz}$ linear probe. The wrist was marked at the distal wrist crease and $2 \mathrm{~cm}$ proximally. Hand and wrist volume were measured using water displacement volumetry.

Results: The intra-rater reliability of volumetry measurements was excellent for both hand and wrist volumetry with a Cronbach alpha of 0.99 and 0.88 respectively. The intra-rater reliability for median nerve measurements was excellent with a Cronbach alpha of 0.96 . The median nerve dimensions were not significantly different between male and female subjects, nor between the dominant and non-dominant hands. The mean median nerve cross sectional area (CSA) at the distal wrist crease was $10.68 \mathrm{~mm}^{2}$ and at a point $2 \mathrm{~cm}$ proximal to this it was $10.18 \mathrm{~mm}^{2}$. The mean difference in CSA between these two points was $0.5 \mathrm{~mm}^{2}$. The median nerve CSA was not significantly related to height, weight or hand size. It was not correlated with hand or wrist volume. No significant differences were found in relation to hand dominance or gender.

Spearman's correlation between median nerve CSA (distal, right wrist) and anthropometric factors

\begin{tabular}{lcc}
\hline & Rho & $\mathrm{p}$ \\
\hline Height & 0.063 & 0.73 \\
Weight & 0.290 & 0.11 \\
BMI & 0.094 & 0.47 \\
Arm Span & 0.115 & 0.38 \\
Finger Span & 0.024 & 0.85 \\
Wrist Circumference & 0.095 & 0.46 \\
Hand Volume & 0.102 & 0.44 \\
Wrist Volume & 0.244 & 0.19
\end{tabular}

Conclusions: Anthropometric factors including BMI, hand/wrist volume were not found to be closely related to median nerve size in normal individuals.

References:

[1] Cartwright MS et al. Ultrasonographic reference values for assessing the normal median nerve in adults. J Neuroimaging. 2009;19(1):47-51.

Disclosure of Interest: None declared

DOI: 10.1136/annrheumdis-2017-eular.3834

\section{FRI0635 DESCRIPTION OF VIDEOCAPILLAROSCOPY OF THE LABIAL MUCOSA IN COMPARISON WITH NAILFOLD VIDEOCAPILLAROSCOPY IN SCLERODERMA}

A.M. Beron, S. Sapag duran, H. Laborde, G. Medina, M. Garcia Carrasco, G. Nasswetter, D. Dubinsky. Rheumatology, Clinical Hospital "Jose de San Martin", University of Buenos Aires., CABA, Argentina

Background: Capillary bed of labial mucosa may be a potentially useful area for assessing abnormalities on the microcirculation. Videocapilaroscopy of the labial mucosa (LVC) in 12/13 scleroderma (SCL) patients showed capillaries disturbance such as great disorganization and anarchic orientation ${ }^{(1)}$.

Objectives: To describe LVC features in SCL and compare them with healthy controls. (HC). To compare nailfold videocapillaroscopy (NVC) with LVC in HC and SCL patients.

Methods: $\geq 16$ years old patients with SCL (ACR-EULAR 2013) were included consecutively since June to July 2016. Smoking patients were excluded. For the evaluation of the LVC we performed a general displaying and then we studied following areas: a-central ( $1 \mathrm{~cm}$ from the frenulum), b-lateral right and left (both 2 $\mathrm{cm}$ from the frenulum) and c-labial border. For evaluation of the NVC, 200x images were obtained from 2nd to 4th fingers both hands and was classified according Cutolo in early, active, late patterns ${ }^{(2)}$. For assesment through LVC: photographs (200x) for each subject were taken. We define quantitative characteristics as means of: capillary diameter, length and density. The average of these parameters was obtained from the evaluation of capillaries included in $1 \mathrm{~mm}^{2}$ of at least 2 continuous images. In addition, the visibility of the subpapillary venous plexus, architecture, dilatation of capillaries, presence of megacapillaries and avascular areas were qualitatively evaluated (photo 1). Each image was reviewed by two experienced observers. We conducted the same process describe above for each healthy control subject.

Results: Twenty two patients were included (18 female, age $47 \pm 11$ ys) with SCL (limited 17, diffuse 5); NVC pattern: early 8, active 11, late 3 . Healthy subjects 12 (11 female, age: $34 \pm 10$ years).

Average capillary density: $17 \pm 4.13(13-26)$ in SCL vs $21 \pm 3.65(16-28)$ in HC (p 0.00).

Average capillary diameter: $43 \pm 13.54$ (17-83) SCL vs $19 \pm 1.67 \mu \mathrm{m}(16-21) \mathrm{HC}$ (p 0.02).

Mean capillary length: $185 \pm 34 \mu \mathrm{m}(125-248)$ SCL vs $237 \pm 42 \mu \mathrm{m}(178-313) \mathrm{HC}$ (p 0.00).

In 22 SCL patients were observed dilated capillaries in 20 (90\%), megacapillaries $(\geq 70 \mu \mathrm{m})$ in $10(45 \%)$ and $7(32 \%)$ showed disturbed architecture with lost areas of the normal $U$-shape and changes in the parallelism of the main axis of the 